\title{
FACTORS IN THE TREATMENT OF LAENNEC'S CIRRHOSIS. I. CLINICAL AND HISTOLOGICAL CHANGES OBSERVED DURING A CONTROL PERIOD OF BED-REST, ALCOHOL WITH- DRAWAL, AND A MINIMAL BASIC DIET 1,2
}

\author{
BY GERALD KLATSKIN AND RAYMOND YESNER \\ (From the Department of Internal Medicine, Yale University School of Medicine, New Haven, \\ Conn., and the Department of Pathology, Veterans Administration \\ Hospital, Newington, Conn.)
}

(Received for publication February 25, 1949)

Fatty infiltration and cirrhosis of the liver can be produced experimentally in animals by defective diets, and can be prevented or cured by supplements of protein or lipotropes (1-10). Clinical observations suggest that dietary deficiency may also play a role in the pathogenesis of Laennec's cirrhosis in man (11), and a number of investigators have reported that dietary supplements of protein, vitamins and lipotropes affect the course of the disease favorably (11-18).

While it is generally agreed that these dietary supplements are of therapeutic value in human cirrhosis, it is still not known whether all are essential, whether their effects are due to a specific action on the liver, or to a more general one on the associated malnutrition, and whether the results of treatment are influenced by non-dietary factors. The difficulty in obtaining suitable controls, and the tendency to use multiple therapeutic measures simultaneously have delayed the solution of these problems.

The results of dietary therapy in cirrhosis are usually evaluated in one of two ways. In the first, longevity statistics are used as the criterion for comparing treated and untreated groups, the latter having usually been observed some years previously $(11,15,16)$. In the other, the effects of various dietary measures are compared either in the same patient or in small groups, using serial clinical, functional and, in some instances, histological observations as the basis for comparison (13, $14,17,18)$. There are valid objections to both methods, but serial observations during alternating

\footnotetext{
1 Supported by a grant from the Veterans Administration.

2 Published with permission of the Chief Medical Director, Department of Medicine and Surgery, Veterans Administration, who assumes no responsibility for the opinions expressed or conclusions drawn by the author.
}

courses of therapy in the same subject appear to offer the most practical means for conducting experiments under controlled conditions.

The natural history of Laennec's cirrhosis and its clinical and morphological manifestations are so variable that observations based on small groups are difficult to interpret, even when the rigid criteria of Volwiler (18) are met. Longevity statistics are even more difficult to analyze, especially when the controls have been observed some years before the experimental subjects. The difficulty in obtaining complete and reliable follow-up data in a large series, the relatively high mortality from unrelated diseases and the changing outlook in the treatment of the two most common serious complications, hemorrhage and infection, are some of the factors which distort the results. The importance of the experimental method and the type of control employed is well illustrated by the conflicting reports of Patek and Post (11) and Wade (19) on the effects of dietary therapy in cirrhosis, and of Volwiler (18) and Beams (14) on the effects of lipotropic substances.

Alcohol withdrawal and bed-rest are often factors in therapeutic experiments in cirrhosis, but are seldom taken into account in evaluating the results. The position of alcohol in the pathogenesis of Laennec's cirrhosis is still uncertain. Alcoholism is now generally regarded as an important factor conditioning malnutrition, but is not thought to have any more direct effect on the liver $(11,18)$. While there is no good evidence that alcohol acts directly as an hepatotoxin, several experiments suggest that it can play a role in the production of cirrhosis independent of its effects on food intake (20).

The importance of bed-rest has been stressed in infectious hepatitis (21), and may well be of 
significance in the treatment of Laennec's cirrhosis (18).

During the past year we have been investigating the effects of dietary supplements of choline and protein in the treatment of Laennec's cirrhosis. As a preliminary each subject has been observed during a control period of three to seven weeks under conditions of complete bed-rest, alcohol withdrawal and a basic diet. Such striking changes have occurred during this period that the original experiments designed to test the efficacy of dietary supplements have had to be revised and then delayed. The following is a report on the clinical, functional and histological changes observed during the control period in 14 subjects.

\section{MATERIAL AND METHODS}

The 14 subjects chosen for investigation were routine admissions to the wards of the New Haven Hospital and the Newington Veterans Hospital. With one exception all had moderate to advanced Laennec's cirrhosis and were admitted because of symptoms referable to it (Table I, Figure 1). Case 9v had a severe fatty infiltration of the liver without fibrosis and was admitted because of a small hemoptysis secondary to bronchiectasis. This patient was included in the series on the assumption that fatty infiltration of this type represents an early stage of Laennec's cirrhosis (22).

There was no selection of cases, all proved cases of Laennec's cirrhosis admitted to the wards of both hospitals being included in the study, provided they were able to stay in the hospital for a minimum of three weeks, were able to take food by mouth, and had not received intensive treatment before admission. All treatment prior to the beginning of the control period is indicated in Table II.

Each of the subjects had the liver function tests outlined below at one- or two-week intervals, and a liver biopsy by Vim-Silverman needle at the beginning and end of each experimental period. The two biopsy sites were never more than a centimeter apart. The site chosen depended on the size and position of the liver, and was epigastric in Cases $1,2 \mathrm{v}, 3,4,6,8 \mathrm{v}, 9 \mathrm{v}, 11 \mathrm{v}$ and 12 , right subcostal in Cases $5 v, 7 v$ and $13 v$, and right intercostal in Cases 10 and 14.

TABLE I

Summary of findings on admission to hospital

\begin{tabular}{|c|c|c|c|c|c|c|c|c|c|c|c|c|c|c|}
\hline & 1 & $2 v$ & 3 & 4 & v & 6 & $7 \mathrm{v}$ & $\mathbf{B v}$ & $9 v$ & 10 & iv & 12 & $3 v$ & 14 \\
\hline $\begin{array}{l}\text { Age, years } \\
\text { Sex } \\
\text { Alcoholism } \\
\text { Inadequate diet } \\
\text { Symptoms, duration } \\
\text { jaundice } \\
\text { ascites } \\
\text { edema } \\
\text { dyspnea } \\
\text { dyspepsia and anorexia } \\
\text { hematemesis } \\
\text { diarrhea } \\
\text { wt. loss, lbs. } \\
\text { duration } \\
\text { Physical findings, severity } \\
\text { malnutrition } \\
\text { jaundice } \\
\text { ascites } \\
\text { edema } \\
\text { pleural effusion } \\
\text { spider nevi } \\
\text { liver } \\
\text { hepatomegaly } \\
\text { induration } \\
\text { splenomegaly } \\
\text { venous collaterals } \\
\text { esoph. varices (x-ray) } \\
\text { fever (max.) } \\
\text { Complications }\end{array}$ & $\begin{array}{l}\text { M } \\
3+ \\
2+ \\
8 \mathrm{~d} \\
10 \mathrm{~d} . \\
0 \\
0 \\
0 \\
0 \\
8 \mathrm{~d} . \\
37 \\
\text { ?y. } \\
0 \\
2+ \\
1+ \\
0 \\
0 \\
1+ \\
5 \mathrm{f} \\
3+ \\
1+ \\
2+ \\
+ \\
0 \\
0\end{array}$ & $\begin{array}{l}\text { M } \\
3+ \\
2+ \\
\text { ?d. } \\
\text { 2w. } \\
\text { ?d. } \\
\text { ?d. } \\
0 \\
0 \\
\text { ?m. } \\
? \\
? \\
3+ \\
1+ \\
3+ \\
3+ \\
2+ \\
1+ \\
2 f \\
2+ \\
0 \\
1+ \\
0 \\
101.5 \\
a .\end{array}$ & $\begin{array}{l}53 \\
\mathrm{~F} \\
? 1+ \\
2+ \\
0 \\
10 \mathrm{w} . \\
? \\
10 \mathrm{w} . \\
10 \mathrm{w} . \\
0 \\
10 \mathrm{w} . \\
14 \\
10 \mathrm{w} . \\
2+ \\
0 \\
2+ \\
1+ \\
1+ \\
1+ \\
3 \mathrm{f} \\
2+ \\
0 \\
1+ \\
\overline{101} \\
b .\end{array}$ & \begin{tabular}{|l|}
42 \\
$\mathrm{~F}$ \\
$2+$ \\
$2+$ \\
0 \\
$3 \frac{1}{2} \mathrm{~m}$. \\
$1 \frac{1}{2} \mathrm{y}$. \\
$2 \mathrm{w}$. \\
$2 \mathrm{w}$. \\
0 \\
$3 \frac{1}{2} \mathrm{~m}$. \\
14 \\
$1 \mathrm{y}$. \\
$2+$ \\
0 \\
$1+$ \\
0 \\
0 \\
$1+$ \\
$5 f$ \\
$2+$ \\
$1+$ \\
$2+$ \\
0 \\
0 \\
$c$.
\end{tabular} & $\begin{array}{l}\mathrm{M} \\
3+ \\
0 \\
0 \\
2 \mathrm{w} . \\
2 \mathrm{~m} . \\
0 \\
2 \mathrm{w} . \\
10 \mathrm{~d} . \\
3 \mathrm{w} . \\
8 \\
2 \mathrm{w} . \\
0 \\
1+ \\
1+ \\
0 \\
0 \\
0 \\
8 \mathrm{f} \\
2+ \\
0 \\
1+ \\
0 \\
100\end{array}$ & $\begin{array}{l}\mathrm{M} \\
2+ \\
0 \\
1 \mathrm{~m} . \\
0 \\
2 \mathrm{~m} . \\
1 \mathrm{y} . \\
3 \mathrm{~m} . \\
0 \\
2 \mathrm{~m} . \\
30 \\
3 \mathrm{~m} . \\
0 \\
1+ \\
0 \\
1+ \\
0 \\
0 \\
7 f \\
2+ \\
0 \\
2+ \\
0 \\
102 \\
0\end{array}$ & $\begin{array}{l}43 \\
\mathrm{M} \\
2+ \\
0 \\
? \\
12 \mathrm{~d} . \\
12 \mathrm{~d} . \\
0 \\
? \mathrm{~m} . \\
0 \\
0 \\
8 \\
2 \mathrm{y} . \\
1+ \\
1+ \\
2+ \\
1+ \\
1+ \\
3+ \\
5 \mathrm{f} \\
2+ \\
0 \\
0 \\
0 \\
100.5 \\
0\end{array}$ & $\begin{array}{l}\mathrm{M} \\
2+ \\
0 \\
4 \mathrm{~d} . \\
4 \mathrm{~d} . \\
0 \\
0 \\
1 \mathrm{~m} . \\
0 \\
1 \mathrm{~m} . \\
? \\
1 \mathrm{~m} . \\
2+ \\
1+ \\
2+ \\
1+ \\
1+ \\
1+ \\
3 \mathrm{f} \\
2+ \\
0 \\
2+ \\
+ \\
100.8 \\
0\end{array}$ & $\begin{array}{l}\text { M } \\
3+ \\
2+ \\
0 \\
0 \\
0 \\
0 \\
3 \mathrm{~m} . \\
0 \\
0 \\
0 \\
\\
0 \\
0 \\
0 \\
0 \\
0 \\
0 \\
4 \mathrm{f} \\
0 \\
0 \\
0 \\
0 \\
0\end{array}$ & $\begin{array}{l}00 \\
\mathrm{~F} \\
0 \\
0 \\
2 \mathrm{~d} . \\
1 \mathrm{~m} . \\
0 \\
1 \mathrm{~m} . \\
1 \mathrm{~m} . \\
0 \\
0 \\
? \\
1 \mathrm{~m} . \\
0 \\
1+ \\
2+ \\
0 \\
1+ \\
1+ \\
0 \\
2+ \\
2+ \\
0 \\
102 \\
e .\end{array}$ & $\begin{array}{l}55 \\
\mathrm{M} \\
3+ \\
2+ \\
1 \mathrm{w} . \\
4 \mathrm{~d} . \\
0 \\
4 \mathrm{~d} . \\
3 \mathrm{w} . \\
? 4 \mathrm{~m} . \\
0 \\
? \\
4 \mathrm{~m} . \\
2+ \\
3+ \\
? 1+ \\
0 \\
0 \\
0 \\
5 \mathrm{f} \\
2+ \\
0 \\
2+ \\
0 \\
100\end{array}$ & $\begin{array}{l}48 \\
M \\
3+ \\
3+ \\
0 \\
0 \\
3 \mathrm{w} . \\
0 \\
2 \mathrm{~m} . \\
0 \\
0 \\
17 \\
2 \mathrm{~m} . \\
3+ \\
0 \\
0 \\
2+ \\
0 \\
0 \\
4 f \\
2+ \\
0 \\
0 \\
0 \\
0 \\
f .\end{array}$ & $\begin{array}{l}M \\
2+ \\
3+ \\
1 \mathrm{~m} . \\
0 \\
4 \mathrm{~d} . \\
1 \mathrm{~m} . \\
4 \mathrm{~m} . \\
0 \\
1 \mathrm{~m} . \\
33 \\
4 \mathrm{~m} . \\
3+ \\
1+ \\
0 \\
2+ \\
0 \\
0 \\
4 f \\
2+ \\
1+ \\
0 \\
\frac{100}{100} \\
g .\end{array}$ & $\begin{array}{l}48 \\
\mathrm{M} \\
3+ \\
3+ \\
0 \\
0 \\
9 \mathrm{w} . \\
4 \mathrm{w} . \\
0 \\
9 \mathrm{w} . \\
0 \\
0 \\
? \\
? \\
3+ \\
0 \\
3+ \\
2+ \\
0 \\
3+ \\
0 \\
0 \\
1+ \\
0 \\
101.4 \\
h .\end{array}$ \\
\hline
\end{tabular}

Symbols: $0=$ absent, $1+=$ mild, $2+=$ moderate, $3+=$ severe; $M=$ male, $F=$ female; $d .=$ days, $w$. $=$ weeks, m. = months, $y$. $=$ years; $f=$ fingers breadth below right costal margin.

Complications: $a$. $=$ mild peripheral neuritis, mild ulcerative colitis; $b$. mild glossitis; $c$. asthma; $d$. bronchiectasis and small hemoptysis (cause of admission); e. peritonitis, RLQ abscess drained 2 mos. later, source not determined; $f$. mild glossitis and painful legs, no signs of neuritis; $g$. mild peripheral neuritis; $h$. marked cheilosis, glossitis, unilateral gynecomastia. 


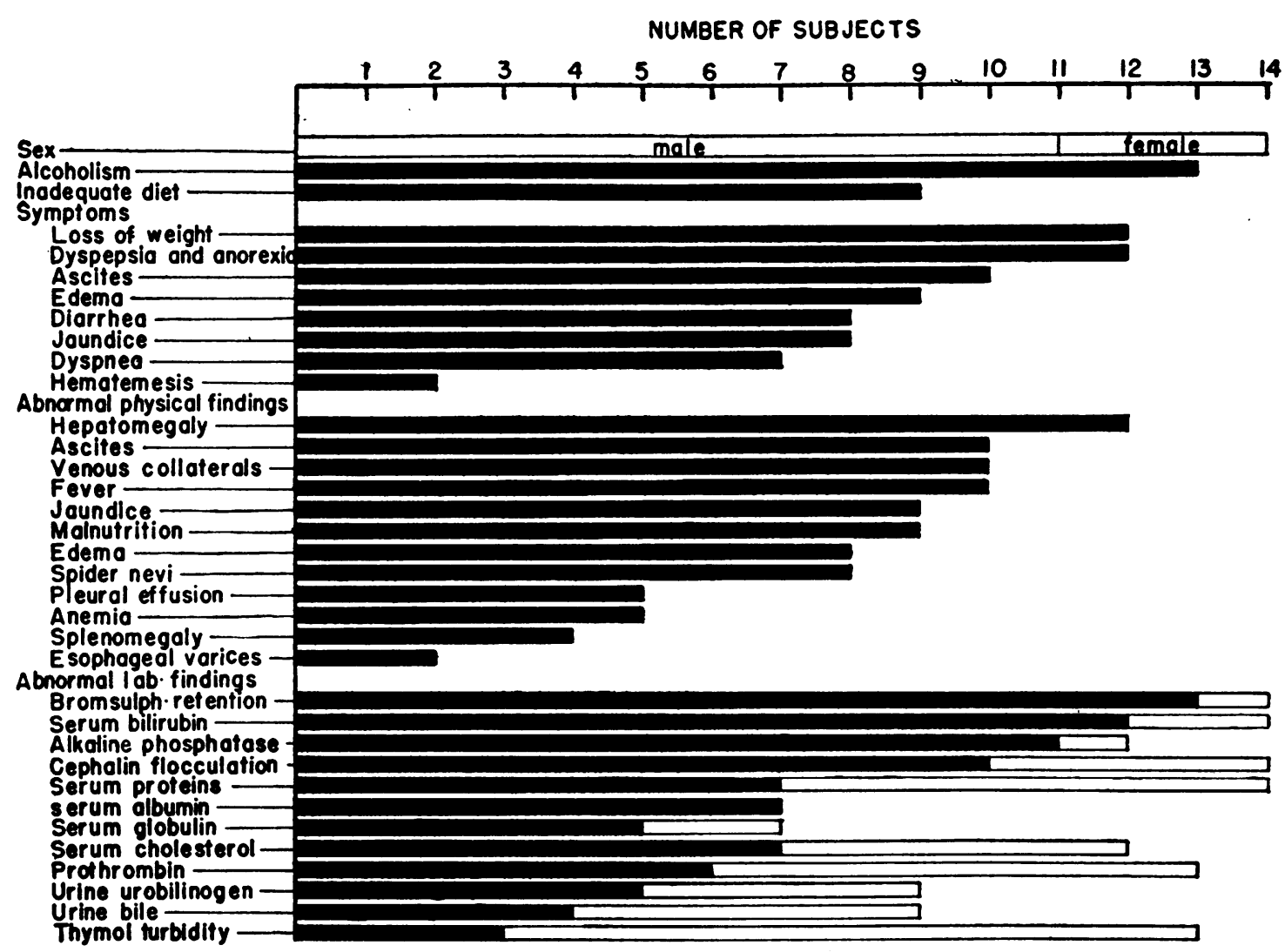

Fig. 1. Clinical Status of Subjects on Admission to the Hospital

The length of the solid bars indicates the number of abnormal findings. The open bars indicate the total number of tests performed.

Esophageal varices demonstrated by X-ray.

Abnormal laboratory values: BSP retention $>5 \%$ in 45 minutes, $>10 \%$ in 30 minutes; serum bilirubin $>1.0 \mathrm{mg} . \%$; alkaline phosphatase $>4.0$ Bodansky or $>12$ King-Armstrong units; cephalin-cholesterol flocculation $>1+$; serum proteins $<6.5 \mathrm{gm} . \%$; serum albumin $<3.0 \mathrm{gm} . \%$; serum cholesterol $<150$ or $>250$ mg. $\%$; prothrombin $<70 \%$; urine urobilinogen $>1: 10$; urine bile $1+$; thymol turbidity $>4.0$ units.

The clinical studies and biopsies were performed by one of us (G. K.), while the other (R. Y.), who had no contact with the subjects nor any knowledge of their clinical status, reviewed all the sections of biopsy material at the end of the experiment, and evaluated them as outlined in Table III. Biopsy material was fixed in $10 \%$ formalin in absolute alcohol, cut at 5 microns and stained with Best's carmine and eosin and hematoxylin. Half the sections were also stained for reticulum and connective tissue with Laidlaw's stain.

The laboratory studies were carried out by identical methods in the two hospitals, with the exceptions noted, and included serum bilirubin (23), cephalin-cholesterol flocculation (24), thymol turbidity (25), bromsulphalein retention (26), serum alkaline phosphatase (27), prothombin (28), urine bilirubin (29) and urine urobilinogen (30). Serum proteins were determined by the macroKjeldahl method at New Haven and the Phillips' falling drop method (31) at Newington. Serum cholesterol was determined by the method of Peters and Man (32) at New Haven and by the Bloor method (33) at Newington. In a few instances the serum alkaline phosphatase was carried out by the King-Armstrong method (34) at New Haven; these values are marked " $K$ " in the tables.

The experimental diet was started within a day or two of the patient's admission to the hospital, with the exceptions noted in Table II, and the patient was kept at bedrest throughout the period of observation. The diet contained $1 \mathrm{gm}$. of protein per kilogram of body weight at the time of admission, allowance being made for accumulated fluid, $100 \mathrm{gm}$. of fat, and enough carbohydrate to raise the total intake to 30 calories per kilogram. Neither vitamins nor other dietary supplements were allowed, with the exception that patients with very low prothrombin levels were given vitamin $\mathrm{K}$.

The control period (Period I) varied in duration from 21 to 49 days. Six of 14 subjects, who were available for further study under the same conditions, received 
TABLE II. Clinical and laboratory observations at the beginning and end of the control period.

\begin{tabular}{|c|c|c|c|c|c|c|c|c|c|c|c|c|c|}
\hline \multirow[b]{2}{*}{ iCase } & \multirow{2}{*}{$\begin{array}{l}\text { Dura- } \\
\text { tion } \\
\text { of } \\
\text { period }\end{array}$} & \multirow{2}{*}{\multicolumn{2}{|c|}{ Diet }} & \multicolumn{8}{|c|}{ Clinical } & \multirow[b]{2}{*}{$\begin{array}{l}1 \text { min. } \\
\text { bili- } \\
\text { rubin }\end{array}$} & \multirow[b]{2}{*}{$\begin{array}{l}\text { Total } \\
\text { bill- } \\
\text { rubin }\end{array}$} \\
\hline & & & & Weight & $\begin{array}{c}\text { Para- } \\
\text { centeses } \\
\text { (number) }\end{array}$ & Ascites & $\underset{\text { dice }}{\text { Jaun- }}$ & Edema & $\begin{array}{l}\text { Hepato- } \\
\text { megaly }\end{array}$ & $\begin{array}{l}\text { Fever } \\
\text { max. }\end{array}$ & $\begin{array}{l}\text { Symp- } \\
\text { toms }\end{array}$ & & \\
\hline 1 & 22 & $\begin{array}{l}\text { P70 F100 C250 } \\
32 \text { calories per } \mathrm{kg} \text {. } \\
\text { All eaten. }\end{array}$ & $\begin{array}{l}\text { B. } \\
\text { E. }\end{array}$ & $\begin{array}{c}k g . \\
69.0 \\
65.5\end{array}$ & 0 & $\begin{array}{l}1+ \\
2+\end{array}$ & $\begin{array}{l}2+ \\
3+\end{array}$ & $\begin{array}{l}0 \\
1+\end{array}$ & $\begin{array}{l}5 f \\
5 f\end{array}$ & $\begin{array}{c}0 \\
102.5\end{array}$ & $\begin{array}{l}2+ \\
1+\end{array}$ & \begin{tabular}{r|}
$m g . \%$ \\
2.41 \\
2.41
\end{tabular} & $\begin{array}{c}m g . \% \\
10.20 \\
14.76\end{array}$ \\
\hline $2 v$ & 28 & $\begin{array}{l}\text { P70 F100 C230 } \\
31 \text { calories per } \mathrm{kg} \text {. } \\
\text { All eaten. }\end{array}$ & $\begin{array}{l}\text { B. } \\
\text { E. }\end{array}$ & $\begin{array}{l}68.2 \\
63.2\end{array}$ & 0 & $\begin{array}{l}2+ \\
0\end{array}$ & $\begin{array}{l}1+ \\
0\end{array}$ & $\begin{array}{l}3+ \\
0\end{array}$ & $\begin{array}{l}2 f \\
\text { 1f }\end{array}$ & $\begin{array}{c}101.5 \\
0\end{array}$ & $\begin{array}{l}3+ \\
1+\end{array}$ & $\begin{array}{l}0.30 \\
0.20\end{array}$ & $\begin{array}{l}1.35 \\
0.85\end{array}$ \\
\hline 3 & 24 & $\begin{array}{l}\text { P60 F100 C180 } \\
36 \text { calories per } \mathrm{kg} \text {. } \\
\text { All eaten. }\end{array}$ & $\begin{array}{l}\text { B. } \\
\text { E. }\end{array}$ & $\begin{array}{l}51.4 \\
52.6\end{array}$ & $\begin{array}{c}4.0 \mathrm{~L} . \\
\text { (1) }\end{array}$ & $\begin{array}{l}2+ \\
1+\end{array}$ & $\begin{array}{l}0 \\
0\end{array}$ & $\begin{array}{l}1+ \\
0\end{array}$ & $\begin{array}{l}3 f \\
3 f\end{array}$ & $\begin{array}{l}101 \\
100\end{array}$ & $\begin{array}{l}2+ \\
1+\end{array}$ & $\begin{array}{l}0.41 \\
0.07\end{array}$ & $\begin{array}{l}1.22 \\
0.61\end{array}$ \\
\hline 4 & 21 & $\begin{array}{l}\text { P70 F100 C200 } \\
32 \text { calories per } \mathrm{kg} . \\
\text { All eaten. }\end{array}$ & $\begin{array}{l}\text { B. } \\
\text { E. }\end{array}$ & $\begin{array}{l}61.4 \\
63.4 \\
\end{array}$ & 0 & $\begin{array}{l}1+ \\
0\end{array}$ & $\begin{array}{l}0 \\
0\end{array}$ & $\begin{array}{l}0 \\
0\end{array}$ & $\begin{array}{l}5 f \\
5 f \\
\end{array}$ & $\begin{array}{l}0 \\
0 \\
\end{array}$ & $\begin{array}{l}2+ \\
0\end{array}$ & $\begin{array}{l}0.07 \\
0.24 \\
\end{array}$ & $\begin{array}{l}0.68 \\
0.68 \\
\end{array}$ \\
\hline $5 v$ & 28 & $\begin{array}{l}\text { P93 F100 C357 } \\
29 \text { calories per } \mathrm{kg} . \\
\text { All eaten. }\end{array}$ & $\begin{array}{l}\text { B. } \\
\text { E. }\end{array}$ & $\begin{array}{l}94.5 \\
96.8\end{array}$ & 0 & $\begin{array}{l}1+ \\
0\end{array}$ & $\begin{array}{l}1+ \\
0\end{array}$ & $\begin{array}{l}0 \\
0\end{array}$ & $\begin{array}{l}8 f \\
8 f\end{array}$ & $\begin{array}{l}100 \\
100\end{array}$ & $\begin{array}{l}2+ \\
1+\end{array}$ & $\begin{array}{l}1.00 \\
0.20\end{array}$ & $\begin{array}{l}2.00 \\
0.70\end{array}$ \\
\hline 6 & 26 & $\begin{array}{l}\text { P70 F100 C250 } \\
24 \text { calories per kg. } \\
\text { All eaten. }\end{array}$ & $\begin{array}{l}\text { B. } \\
\text { E. }\end{array}$ & $\begin{array}{l}92.0 \\
88.9\end{array}$ & 0 & $\begin{array}{l}0 \\
0\end{array}$ & $\begin{array}{l}1+ \\
1+\end{array}$ & $\begin{array}{l}1+ \\
?\end{array}$ & $\begin{array}{l}7 f \\
6 f \\
\end{array}$ & $\begin{array}{r}102 \\
102 \\
\end{array}$ & $\begin{array}{l}2+ \\
1+\end{array}$ & $\begin{array}{l}1.29 \\
0.68\end{array}$ & $\begin{array}{l}2.38 \\
2.38\end{array}$ \\
\hline$\overline{7 v}$ & 42 & $\begin{array}{l}\text { P85 F100 C300 } \\
30 \text { calories per kg. } \\
\text { All eaten. }\end{array}$ & $\begin{array}{l}\text { B. } \\
\text { E. }\end{array}$ & $\begin{array}{l}80.0 \\
75.5 \\
\end{array}$ & $\begin{array}{c}1.0 \mathrm{~L} . \\
(1)\end{array}$ & $\begin{array}{l}2+ \\
0 \\
\end{array}$ & $\begin{array}{l}1+ \\
0\end{array}$ & $\begin{array}{l}1+ \\
0\end{array}$ & $\begin{array}{l}5 f \\
5 f \\
\end{array}$ & $\begin{array}{l}100.5 \\
100 \\
\end{array}$ & $\begin{array}{l}1+ \\
0\end{array}$ & $\begin{array}{l}0.30 \\
0.20 \\
\end{array}$ & $\begin{array}{l}1.85 \\
1.00 \\
\end{array}$ \\
\hline $8 v$ & 35 & $\begin{array}{l}\text { P65 F100 C200 } \\
30 \text { calories per } \mathrm{kg} \text {. } \\
\text { Eaten poorly for half } \\
\text { the period. }\end{array}$ & $\begin{array}{l}\text { B. } \\
\text { E. }\end{array}$ & $\begin{array}{l}65.5 \\
58.0\end{array}$ & $\begin{array}{c}13.9 \mathrm{~L} . \\
(3)\end{array}$ & $\begin{array}{l}2+ \\
2+\end{array}$ & $\begin{array}{l}1+ \\
1+\end{array}$ & $\begin{array}{l}1+ \\
1+\end{array}$ & $\begin{array}{l}3 f \\
3 f\end{array}$ & $\begin{array}{l}100.6 \\
100.4\end{array}$ & $\begin{array}{l}3+ \\
2+\end{array}$ & $\begin{array}{l}1.50 \\
1.55\end{array}$ & $\begin{array}{l}3.10 \\
3.60\end{array}$ \\
\hline$\overline{9 v}$ & 42 & $\begin{array}{l}\text { P70 F100 C230 } \\
29 \text { calories per kg. } \\
\text { All eaten. }\end{array}$ & $\begin{array}{l}\text { B. } \\
\text { E. }\end{array}$ & $\begin{array}{r}72.7 \\
72.7 \\
\end{array}$ & 0 & $\begin{array}{l}0 \\
0\end{array}$ & $\begin{array}{l}0 \\
0 \\
\end{array}$ & $\begin{array}{l}0 \\
0\end{array}$ & $\begin{array}{l}\mathrm{ff} \\
0 \\
\end{array}$ & $\begin{array}{l}0 \\
0\end{array}$ & $\begin{array}{l}1+ \\
0\end{array}$ & $\begin{array}{l}0.03 \\
0.20 \\
\end{array}$ & $\begin{array}{l}1.55 \\
0.85 \\
\end{array}$ \\
\hline 10 & 32 & $\begin{array}{l}\text { P85 F100 C250 } \\
27 \text { calories per kg. } \\
\text { Poorly taken. }\end{array}$ & $\begin{array}{l}\text { B. } \\
\text { E. }\end{array}$ & $\begin{array}{l}83.2 \\
76.5\end{array}$ & $\underset{(2)}{4.0 \mathrm{~L} .}$ & $\begin{array}{l}2+ \\
2+\end{array}$ & $\begin{array}{l}1+ \\
1+\end{array}$ & $\begin{array}{l}0 \\
0\end{array}$ & 0 & $\begin{array}{l}102 \\
102\end{array}$ & $\begin{array}{l}2+ \\
2+\end{array}$ & $\begin{array}{l}0.41 \\
0.27\end{array}$ & $\begin{array}{l}1.70 \\
1.38\end{array}$ \\
\hline $11 v$ & 49 & $\begin{array}{l}\text { P71 F100 C234 } \\
29 \text { calories per } \mathrm{kg} \text {. } \\
\text { All eaten. } \\
\end{array}$ & $\begin{array}{l}\text { B. } \\
\text { E. }\end{array}$ & $\begin{array}{l}72.3 \\
68.6 \\
\end{array}$ & 0 & $\begin{array}{l}21+ \\
0\end{array}$ & $\begin{array}{l}3+ \\
1+\end{array}$ & $\begin{array}{l}0 \\
0\end{array}$ & $\begin{array}{l}5 f \\
2 f\end{array}$ & $\begin{array}{c}100.2 \\
0 \\
\end{array}$ & $\begin{array}{l}3+ \\
0\end{array}$ & \begin{tabular}{r|}
12.00 \\
1.25
\end{tabular} & $\begin{array}{r}17.10 \\
2.70\end{array}$ \\
\hline 12 & 41 & $\begin{array}{l}\text { P55 F80 C515 } \\
60 \text { calories per kg. } \\
\text { Measured intake from } \\
27-60 \text { calories per } \mathrm{kg} \text {. }\end{array}$ & $\begin{array}{l}\text { B. } \\
\text { E. }\end{array}$ & $\begin{array}{l}55.9 \\
57.3\end{array}$ & 0 & $\begin{array}{l}0 \\
0\end{array}$ & $\begin{array}{l}0 \\
0\end{array}$ & $\begin{array}{l}2+ \\
0\end{array}$ & $\begin{array}{l}4 f \\
2 f\end{array}$ & $\begin{array}{l}0 \\
0\end{array}$ & $\begin{array}{l}3+ \\
1+\end{array}$ & $\begin{array}{l}0.34 \\
0.14\end{array}$ & $\begin{array}{l}0.48 \\
0.27\end{array}$ \\
\hline $13 v$ & 38 & $\begin{array}{l}\text { P55 F100 C132 } \\
30 \text { calories per kg. } \\
\text { All eaten. }\end{array}$ & $\begin{array}{l}\text { B. } \\
\text { E. }\end{array}$ & $\begin{array}{l}55.5 \\
55.9\end{array}$ & 0 & $\begin{array}{l}0 \\
0\end{array}$ & $\begin{array}{l}1+ \\
0\end{array}$ & $\begin{array}{l}2+ \\
0\end{array}$ & $\begin{array}{l}4 f \\
4 f\end{array}$ & $\begin{array}{r}100 \\
0\end{array}$ & $\begin{array}{l}2+ \\
0\end{array}$ & $\begin{array}{l}1.25 \\
0.10\end{array}$ & $\begin{array}{l}2.00 \\
0.20\end{array}$ \\
\hline 14 & 32 & $\begin{array}{l}\text { P70 F100 C230 } \\
30 \text { calories per kg. } \\
\text { Poorly taken last } \\
\text { two weeks. }\end{array}$ & $\begin{array}{l}\text { B. } \\
\text { E. }\end{array}$ & $\begin{array}{l}69.5 \\
55.7\end{array}$ & $\underset{(4)}{18.7} \mathrm{~L}$ & $\begin{array}{l}3+ \\
3+\end{array}$ & $\begin{array}{l}0 \\
1+\end{array}$ & $\begin{array}{l}2+ \\
2+\end{array}$ & $\begin{array}{l}0 \\
0\end{array}$ & $\begin{array}{l}100.8 \\
101.4\end{array}$ & $\begin{array}{l}3+ \\
3+\end{array}$ & $\begin{array}{l}0.27 \\
0.85\end{array}$ & $\begin{array}{l}0.38 \\
2.58\end{array}$ \\
\hline
\end{tabular}

Symbols as in Table I. B = beginning, and $\mathrm{E}=$ end of control period.

* Cephalin-cholesterol flocculation: 24 hrs./48 hrs.

† Bromsulphalein retention after $5 \mathrm{mg}$. per $\mathrm{kg}$. of dye intravenously: $30 \mathrm{~min} . / 45 \mathrm{~min}$. 
TABLE II (continued)

\begin{tabular}{|c|c|c|c|c|c|c|c|c|c|c|c|c|c|c|}
\hline \multirow[b]{2}{*}{ Case } & \multicolumn{13}{|c|}{ Laboratory } & \multirow[b]{2}{*}{ Remarks } \\
\hline & $\begin{array}{l}\text { Ceph. } \\
\text { floc:* }\end{array}$ & $\begin{array}{c}\text { Bromsul- } \\
\text { phalein } \\
\text { reten- } \\
\text { tiont } \\
\end{array}$ & $\begin{array}{c}\text { Alk. } \\
\text { phos- } \\
\text { pha- } \\
\text { taseł } \\
\end{array}$ & $\begin{array}{l}\text { Serum } \\
\text { prot. }\end{array}$ & $\begin{array}{c}\text { Serum } \\
\text { alb. }\end{array}$ & $\begin{array}{l}\text { Serum } \\
\text { glob. }\end{array}$ & $\begin{array}{l}\text { Total } \\
\text { cho- } \\
\text { les- } \\
\text { terol } \\
\end{array}$ & 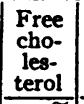 & $\begin{array}{l}\% \\
\text { free } \\
\text { cho- } \\
\text { les.8 } \\
\end{array}$ & \begin{tabular}{|} 
Pro- \\
throm- \\
bin
\end{tabular} & $\begin{array}{c}\text { Urine } \\
\text { bile }\end{array}$ & $\begin{array}{c}\text { Urine } \\
\text { urobi- } \\
\text { linogen }\end{array}$ & $\begin{array}{c}\text { Thymol } \\
\text { turbid- } \\
\text { ity }\end{array} \mid$ & \\
\hline 1 & $\begin{array}{l}1+/ 1+ \\
0 / 0\end{array}$ & $\begin{array}{c}\% \\
51 / \\
-\end{array}$ & $\begin{array}{c}\text { units } \\
3.52 \\
2.20\end{array}$ & $\begin{array}{l}8 m . \% \\
7.05 \\
5.84\end{array}$ & $\begin{array}{l}8 m . \% \\
2.50 \\
2.77\end{array}$ & $\begin{array}{l}8 m . \% \\
4.55 \\
3.07\end{array}$ & \begin{tabular}{c|}
$m g . \%$ \\
112 \\
146
\end{tabular} & \begin{tabular}{c|}
$m g . \%$ \\
88 \\
99
\end{tabular} & $\begin{array}{l}79 \\
68\end{array}$ & $\begin{array}{l}\% \\
70 \\
62\end{array}$ & $\begin{array}{l}4+ \\
4+\end{array}$ & $\begin{array}{l}1: 10 \\
1: 160\end{array}$ & $\begin{array}{l}\text { units } \\
4.0 \\
3.0\end{array}$ & $\begin{array}{l}\text { Clinical and functional im- } \\
\text { provement until 14th day } \\
\text { when pt. developed sore } \\
\text { throat and fever, following } \\
\text { which relapse occurred. } \\
\text { Obviously lost tissue. }\end{array}$ \\
\hline $2 v$ & $\begin{array}{l}13+ \\
13+\end{array}$ & $\begin{array}{l}/ 28.5 \\
/ 4.5\end{array}$ & $\begin{array}{l}7.70 \\
8.80\end{array}$ & $\begin{array}{l}7.44 \\
8.45\end{array}$ & - & - & $\begin{array}{l}134 \\
245\end{array}$ & - & - & $\begin{array}{l}35 \\
68\end{array}$ & $\begin{array}{l}\text { tr. } \\
-\end{array}$ & - & $\begin{array}{l}5.5 \\
6.0\end{array}$ & $\begin{array}{l}\text { Obviously lost tissue and } \\
\text { wanted more food. During } \\
\text { week before study received } \\
\text { choline } 4.0 \mathrm{gm} \text {. and meth- } \\
\text { ionine } 4.0 \mathrm{gm} \text {. daily and } \\
\text { had two paracenteses. }\end{array}$ \\
\hline 3 & $\begin{array}{l}0 / 0 \\
0 / 0\end{array}$ & $\begin{array}{l}42.9 / \\
9.3 /\end{array}$ & $\begin{array}{l}8.10 \\
5.28\end{array}$ & $\begin{array}{l}6.30 \\
6.98\end{array}$ & $\begin{array}{l}1.21 \\
2.15\end{array}$ & $\begin{array}{l}5.09 \\
4.83\end{array}$ & $\begin{array}{r}88 \\
168\end{array}$ & $\begin{array}{l}34 \\
51\end{array}$ & $\begin{array}{l}39 \\
33\end{array}$ & $\begin{array}{r}100 \\
-\end{array}$ & $\begin{array}{l}0 \\
0\end{array}$ & $\begin{array}{c}1: 40 \\
0\end{array}$ & $\begin{array}{l}3.5 \\
3.0\end{array}$ & $\begin{array}{l}\text { During week before study } \\
\text { received high protein diet } \\
\text { and had paracentesis of } 5.7 \\
\text { L. Gained tissue on experi- } \\
\text { mental diet. }\end{array}$ \\
\hline 4 & $\begin{array}{l}0 / 0 \\
0 / 0 \\
\end{array}$ & $\begin{array}{l}36 / \\
21.6 / \\
\end{array}$ & $\begin{array}{l}11.43 \\
17.00 \\
\end{array}$ & $\begin{array}{l}7.02 \\
6.20 \\
\end{array}$ & $\begin{array}{l}2.77 \\
2.58 \\
\end{array}$ & $\begin{array}{l}4.25 \\
3.62 \\
\end{array}$ & $\begin{array}{r}196 \\
- \\
\end{array}$ & $\begin{array}{l}63 \\
- \\
\end{array}$ & $\begin{array}{r}32 \\
- \\
\end{array}$ & $\begin{array}{r}100 \\
- \\
\end{array}$ & $\begin{array}{c}1+ \\
0 \\
\end{array}$ & $\begin{array}{l}1: 20 \\
1: 20 \\
\end{array}$ & $\begin{array}{l}2.0 \\
2.0 \\
\end{array}$ & \\
\hline $5 v$ & $\begin{array}{l}13+ \\
13+\end{array}$ & $\begin{array}{l}26.5 / \\
16.0\end{array}$ & $\begin{array}{l}5.1 \\
1.2\end{array}$ & $\begin{array}{l}7.15 \\
7.80\end{array}$ & - & - & $\begin{array}{r}233 \\
198\end{array}$ & - & - & $\begin{array}{l}85 \\
51\end{array}$ & $\begin{array}{l}0 \\
-\end{array}$ & $\begin{array}{l}1+ \\
-\end{array}$ & $\begin{array}{l}6.5 \\
3.0\end{array}$ & $\begin{array}{l}\text { During week before study } \\
\text { received high protein diet, } \\
\text { which was very poorly } \\
\text { taken, and had paracen- } \\
\text { tesis which yielded a small } \\
\text { amount fluid. }\end{array}$ \\
\hline 6 & $\begin{array}{l}3+/ 4+ \\
2+14+ \\
\end{array}$ & $\begin{array}{l}40 / \\
36 /\end{array}$ & - & $\begin{array}{l}5.60 \\
6.77 \\
\end{array}$ & $\begin{array}{l}1.35 \\
1.37 \\
\end{array}$ & \begin{tabular}{|l|}
4.26 \\
5.40 \\
\end{tabular} & - & - & - & $\begin{array}{r}55 \\
- \\
\end{array}$ & - & - & $\begin{array}{r}6.5 \\
20.0 \\
\end{array}$ & $\begin{array}{l}\text { Regular diet for five days } \\
\text { before study. }\end{array}$ \\
\hline $7 v$ & $\begin{array}{l}13+ \\
12+ \\
\end{array}$ & $\begin{array}{l}124 \\
129 \\
\end{array}$ & $\begin{array}{l}7.40 \\
7.60 \\
\end{array}$ & $\begin{array}{r}7.80 \\
7.80 \\
\end{array}$ & - & - & $\begin{array}{l}135 \\
166 \\
\end{array}$ & - & - & $\begin{array}{r}100 \\
- \\
\end{array}$ & - & - & $\begin{array}{l}1.5 \\
2.0 \\
\end{array}$ & $\begin{array}{l}\text { Paracentesis performed sec- } \\
\text { ond day of study-no re- } \\
\text { currence of fluid. }\end{array}$ \\
\hline $8 v$ & $\begin{array}{l}14+ \\
13+\end{array}$ & $\begin{array}{r}149 \\
-\end{array}$ & $\begin{array}{l}6.6 \\
5.3\end{array}$ & $\begin{array}{l}5.10 \\
5.20\end{array}$ & - & - & $\begin{array}{l}176 \\
186\end{array}$ & - & - & $\begin{array}{r}51 \\
-\end{array}$ & $\begin{array}{l}3+ \\
-\end{array}$ & $\begin{array}{l}4+ \\
-\end{array}$ & $\begin{array}{l}2.0 \\
3.0\end{array}$ & $\begin{array}{l}\text { During 17-day period before } \\
\text { study received high protein } \\
\text { diet and had paracentesis of } \\
4.1 \mathrm{~L} \text {. Severe hematemesis } \\
13 \text { th day of study, requir- } \\
\text { ing } 5.0 \mathrm{~L} \text {. of blood. }\end{array}$ \\
\hline $9 v$ & $\begin{array}{l}10 \\
11+ \\
\end{array}$ & $\begin{array}{l}110.5 \\
10 \\
\end{array}$ & - & $\begin{array}{l}7.40 \\
- \\
\end{array}$ & - & - & $\begin{array}{l}205 \\
260 \\
\end{array}$ & - & - & - & $\begin{array}{l}0 \\
0 \\
\end{array}$ & - & $\begin{array}{l}2.5 \\
2.0 \\
\end{array}$ & \\
\hline 10 & $\begin{array}{l}1+/ 2+ \\
2+/ 4+\end{array}$ & $\begin{array}{l}32 / \\
40 /\end{array}$ & $7.5 \mathrm{k}$ & 4.79 & 1.61 & $\begin{array}{l}2.80 \\
3.18\end{array}$ & 100 & - & - & 55 & - & $1: 80$ & $\begin{array}{l}1.0 \\
1.0\end{array}$ & $\begin{array}{l}\text { Paracentesis (X2) of } 9.16 \mathrm{~L} \text {. } \\
\text { and low fat diet during 11- } \\
\text { day period before study. } \\
\text { Signs of peritonitis, oper- } \\
\text { ation refused. Abscess } \\
\text { drained two months later, } \\
\text { initial site undetermined. } \\
\text { Obviously lost tissue. } \\
\end{array}$ \\
\hline $11 \mathrm{v}$ & $\begin{array}{l}13+ \\
10 \\
\end{array}$ & $\begin{array}{l}136 \\
124.5 \\
\end{array}$ & $\begin{array}{r}13.6 \\
7.0 \\
\end{array}$ & $\begin{array}{l}6.30 \\
7.80 \\
\end{array}$ & - & - & $\begin{array}{l}460 \\
360 \\
\end{array}$ & - & - & $\begin{array}{l}50 \\
65 \\
\end{array}$ & - & - & $\begin{array}{l}4.0 \\
3.0 \\
\end{array}$ & \\
\hline 12 & $\begin{array}{l}1+/ 2+ \\
1+/ 2+\end{array}$ & $\begin{array}{l}20 / \\
4 /\end{array}$ & $\begin{array}{r}13.4 k \\
8.1 k\end{array}$ & $\begin{array}{l}5.35 \\
6.00\end{array}$ & $\begin{array}{l}2.96 \\
3.07\end{array}$ & \begin{tabular}{|l|}
2.39 \\
2.93
\end{tabular} & $\begin{array}{l}126 \\
172\end{array}$ & $\begin{array}{l}38 \\
54\end{array}$ & $\begin{array}{l}30 \\
31\end{array}$ & $\begin{array}{r}100 \\
-\end{array}$ & $\begin{array}{l}0 \\
-\end{array}$ & $\begin{array}{c}1: 32 \\
-\end{array}$ & $\begin{array}{l}4.0 \\
1.0\end{array}$ & \\
\hline $13 v$ & $\begin{array}{l}13+ \\
12+\end{array}$ & $\begin{array}{l}10 \\
10\end{array}$ & $\begin{array}{l}6.9 \\
4.2\end{array}$ & $\begin{array}{l}6.3 \\
7.8\end{array}$ & - & - & $\begin{array}{l}308 \\
268\end{array}$ & - & - & $\begin{array}{l}63 \\
50\end{array}$ & - & - & $\begin{array}{l}1.00 \\
3.75\end{array}$ & $\begin{array}{l}\text { Vitamin B complex paren- } \\
\text { terally first seven days of } \\
\text { study. Gained tissue as } \\
\text { edema subsided. Wanted } \\
\text { more food. }\end{array}$ \\
\hline 14 & $\begin{array}{l}3+/ 4+ \\
3+/ 4+\end{array}$ & $\begin{array}{r}145 \\
-\end{array}$ & $\begin{array}{l}19.5 \mathrm{k} \\
13.3 \mathrm{k}\end{array}$ & $\begin{array}{l}6.30 \\
5.79\end{array}$ & $\begin{array}{l}2.35 \\
1.38\end{array}$ & $\begin{array}{l}3.95 \\
4.41\end{array}$ & 170 & $\begin{array}{l}56 \\
-\end{array}$ & $\begin{array}{r}33 \\
-\end{array}$ & $\begin{array}{l}55 \\
55\end{array}$ & $\begin{array}{c}- \\
1+\end{array}$ & $\begin{array}{c}0 \\
1: 40\end{array}$ & $\begin{array}{l}5.0 \\
5.0\end{array}$ & $\begin{array}{l}\text { Clinical improvement first } \\
\text { three weeks, then downhill } \\
\text { course with increasing ano- } \\
\text { rexia, ascites and weight } \\
\text { loss. }\end{array}$ \\
\hline
\end{tabular}

Bodansky units, except for values marked $\mathbf{k}$. (King-Armstrong units).

$\frac{\text { Free }}{\text { Total }}$ cholesterol, per cent. 
TABLE III

Histology of the liver at the beginning and end of the control period

\begin{tabular}{|c|c|c|c|c|c|c|c|c|c|c|c|c|c|c|}
\hline \multirow{2}{*}{\multicolumn{2}{|c|}{ Case }} & \multicolumn{3}{|c|}{ Fat infiltration } & \multicolumn{2}{|c|}{ Pigment } & \multicolumn{2}{|c|}{ Necrosis } & \multicolumn{2}{|c|}{ Cellular infilt. } & \multirow{2}{*}{$\begin{array}{c}\text { Pleomor- } \\
\text { phism }\end{array}$} & \multirow{2}{*}{ Fibrosis } & \multirow{2}{*}{$\begin{array}{c}\text { Bile } \\
\text { duct } \\
\text { prolif. }\end{array}$} & \multirow{2}{*}{$\begin{array}{c}\text { Intra- } \\
\text { lobular } \\
\text { disorgani- } \\
\text { zation }\end{array}$} \\
\hline & & Degree & $\begin{array}{c}\text { Droplet } \\
\text { size }\end{array}$ & $\begin{array}{l}\text { Distri- } \\
\text { bution } \dagger\end{array}$ & $\begin{array}{l}\text { Intra- } \\
\text { cellular }\end{array}$ & $\begin{array}{c}\text { Bile } \\
\text { thrombi }\end{array}$ & Hyalin & Focal & $\underset{\text { typeł }}{\text { Cell }}$ & Degree & & & & \\
\hline 1 & $\begin{array}{l}\text { B.** } \\
\text { E. }\end{array}$ & +++ & +++ & $\underset{T}{T}$ & ++ & ++++ & +++ & $\begin{array}{l}0 \\
0\end{array}$ & $\mathrm{~L}_{\mathrm{PLM}}$ & ++ & $\begin{array}{l}+++ \\
+++\end{array}$ & ++++ & ++ & ++++ \\
\hline $2 v$ & B. & +++ & +++ & $\stackrel{T}{M C}$ & $\begin{array}{l}0 \\
0\end{array}$ & $\begin{array}{r}0 \\
\pm \\
\end{array}$ & $\begin{array}{l}0 \\
0 \\
\end{array}$ & $\begin{array}{l} \pm \\
\pm\end{array}$ & $\begin{array}{l}\text { PLM } \\
\text { PLME }\end{array}$ & \pm & ++ & ++++ & ++++ & $\begin{array}{r}+++ \\
+++\end{array}$ \\
\hline 3 & $\begin{array}{l}\text { B. } \\
\text { E. }\end{array}$ & ++ & $+t$ & $\begin{array}{l}T \\
T\end{array}$ & + & $\begin{array}{l}+ \\
\pm\end{array}$ & $\begin{array}{l}0 \\
0\end{array}$ & $\begin{array}{l}0 \\
0\end{array}$ & $\begin{array}{l}\mathrm{LM} \\
\mathrm{LM}\end{array}$ & ++ & ++ & ++++ & ++++ & ++++ \\
\hline 4 & $\begin{array}{l}\text { B. } \\
\text { E. }\end{array}$ & $\begin{array}{l}+++ \\
++\end{array}$ & $+t$ & $\mathrm{~T}$ & $\begin{array}{l}0 \\
0\end{array}$ & $\begin{array}{l}0 \\
0 \\
\end{array}$ & + & o & $\begin{array}{l}\text { LM } \\
\text { LM }\end{array}$ & ++ & \pm & $\begin{array}{l}++++ \\
++++\end{array}$ & $\begin{array}{l}++++ \\
++++\end{array}$ & $\begin{array}{l}+++ \\
++++ \\
\end{array}$ \\
\hline $5 \mathrm{v}$ & $\begin{array}{l}\text { B. } \\
\text { E. }\end{array}$ & ++++ & $\begin{array}{l}+++ \\
+++ \\
\end{array}$ & $\begin{array}{l}T \\
T\end{array}$ & + & $\begin{array}{r}+++ \\
++ \\
\end{array}$ & $\begin{array}{l}0 \\
0 \\
\end{array}$ & $\begin{array}{l}0 \\
0\end{array}$ & $\begin{array}{l}\text { LM } \\
\text { LMP }\end{array}$ & $\begin{array}{r}+++ \\
++ \\
\end{array}$ & $\begin{array}{r}++ \\
+++ \\
\end{array}$ & $\begin{array}{l}++++ \\
++++\end{array}$ & $\begin{array}{r}+++ \\
++++\end{array}$ & $\begin{array}{l}++++ \\
++++ \\
\end{array}$ \\
\hline 6 & $\begin{array}{l}\text { B. } \\
\mathbf{E}\end{array}$ & +++ & $\begin{array}{r}++ \\
+++ \\
\end{array}$ & $\begin{array}{l}T \\
T\end{array}$ & $\begin{array}{l}\mathbf{0} \\
\mathbf{0}\end{array}$ & $\begin{array}{l}\mathbf{0} \\
\mathbf{0} \\
\end{array}$ & $\begin{array}{l}++ \\
++ \\
\end{array}$ & $\begin{array}{l}0 \\
0\end{array}$ & $\begin{array}{l}\text { LM } \\
\text { LM }\end{array}$ & \pm & $\begin{array}{r}+++ \\
++++\end{array}$ & $\begin{array}{l}++++ \\
++++\end{array}$ & ++++ & ++++ \\
\hline $7 v$ & B. & $\begin{array}{r}++ \\
\pm \\
\end{array}$ & \pm & $\begin{array}{l}\mathbf{C} \\
\mathbf{C}\end{array}$ & 士 & $\begin{array}{l}\mathbf{0} \\
\mathbf{0} \\
\end{array}$ & $\begin{array}{l}0 \\
0 \\
\end{array}$ & $\begin{array}{r}++ \\
\pm \\
\end{array}$ & $\begin{array}{l}\text { LMP } \\
\text { LM }\end{array}$ & ++ & $\begin{array}{r}++++ \\
++ \\
\end{array}$ & $\begin{array}{l}+++ \\
+++ \\
\end{array}$ & ++ & ++++ \\
\hline $8 v$ & B. & ++ & ++ & $\stackrel{T}{T}$ & $\begin{array}{l}0 \\
0\end{array}$ & $\begin{array}{c}+ \\
0 \\
\end{array}$ & $\begin{array}{r}++++ \\
+ \\
\end{array}$ & $\begin{array}{l}0 \\
0\end{array}$ & $\begin{array}{l}\mathrm{PL} \\
\mathrm{PL} \\
\end{array}$ & ++ & ++++ & $\begin{array}{l}++++ \\
+++\end{array}$ & $\begin{array}{r}+++ \\
++ \\
\end{array}$ & $\begin{array}{l}+++ \\
+++ \\
\end{array}$ \\
\hline $9 \mathrm{v}$ & $\begin{array}{l}\text { B. } \\
\text { E. }\end{array}$ & $\begin{array}{r}++++ \\
++ \\
\end{array}$ & $\begin{array}{r}+++ \\
+++ \\
\end{array}$ & $\begin{array}{l}\mathrm{T} \\
\mathrm{CM}\end{array}$ & 圭 & \pm & $\begin{array}{l}\mathbf{0} \\
\mathbf{0}\end{array}$ & $t$ & $\begin{array}{l}\text { PL } \\
\mathbf{L}\end{array}$ & \pm & ++ & $\begin{array}{l}0 \\
\pm \\
\end{array}$ & $\begin{array}{l}0 \\
0 \\
\end{array}$ & ++++ \\
\hline 10 & $\begin{array}{l}\text { B. } \\
\text { E. }\end{array}$ & ++ & +++ & $\underset{T}{T}$ & $\begin{array}{l}\mathbf{0} \\
\mathbf{0}\end{array}$ & $\begin{array}{l}0 \\
0 \\
\end{array}$ & $\begin{array}{l}0 \\
\pm \\
\end{array}$ & $\begin{array}{l}0 \\
0 \\
\end{array}$ & $\begin{array}{l}\mathrm{L} \\
\mathbf{0}\end{array}$ & ++ & $\begin{array}{r} \pm \\
++ \\
\end{array}$ & ++++ & +++ & $\begin{array}{r}+++ \\
++++ \\
\end{array}$ \\
\hline $11 \mathrm{v}$ & $\begin{array}{l}\text { B. } \\
\text { E. }\end{array}$ & ++++ & $\begin{array}{r}++++ \\
++ \\
\end{array}$ & $\underset{T}{T}$ & \pm & $\begin{array}{r}++ \\
\pm \\
\end{array}$ & $\begin{array}{l}\mathbf{0} \\
\mathbf{0} \\
\end{array}$ & \pm & $\begin{array}{l}\mathrm{P} \\
\mathrm{PM} \\
\end{array}$ & \pm & \pm & \pm+ & $\begin{array}{l}++ \\
++ \\
\end{array}$ & ++ \\
\hline 12 & $\begin{array}{l}\text { B. } \\
\text { E. }\end{array}$ & +++ & ++++ & $\underset{T}{T}$ & $\stackrel{0}{+}$ & $\mathbf{0}$ & $\stackrel{+}{0}$ & $\begin{array}{l}0 \\
0\end{array}$ & $\frac{\mathrm{ME}}{\mathrm{ME}}$ & $+\stackrel{ \pm}{+}$ & $+⿱ 亠+口$ & ++ & ++ & ++ \\
\hline $13 \mathrm{v}$ & B. & ++ & ++ & $\begin{array}{l}T \\
0\end{array}$ & ++ & ++++ & $\begin{array}{l}0 \\
0\end{array}$ & $\begin{array}{l}\mathbf{0} \\
\mathbf{0}\end{array}$ & $\begin{array}{l}0 \\
\mathrm{~L}\end{array}$ & $\begin{array}{l}0 \\
\pm\end{array}$ & + & ++ & ++ & ++ \\
\hline 14 & $\begin{array}{l}\text { B. } \\
\text { E. }\end{array}$ & $\begin{array}{l} \pm \\
\pm\end{array}$ & $+t$ & $\begin{array}{l}\text { C } \\
\text { C }\end{array}$ & $\begin{array}{l}0 \\
\mathbf{0}\end{array}$ & $\begin{array}{l}0 \\
0\end{array}$ & +++ & $\begin{array}{l}0 \\
0\end{array}$ & $\begin{array}{l}\text { PLE } \\
\text { PME }\end{array}$ & + & ++ & ++++ & +++ & +++ \\
\hline
\end{tabular}

* B. = beginning, and E. = end of control period.

$\dagger \mathrm{T}=$ throughout lobule, $\mathrm{C}=$ central, $\mathrm{M}=$ mid-zonal.

$\mathrm{L}=$ lymphocytes, $\mathrm{M}=$ monocytes, $\mathrm{P}=$ polymorphonuclears, $\mathrm{E}=$ eosinophiles, $\mathrm{P}=$ plasma cells.

supplements of choline (Period II) and protein (Period III), in addition to the basic diet, following completion of the control period.

The present report is concerned primarily with observations made during Period $I$. The experiments dealing with the effects of dietary supplements are still in progress and will be discussed only briefly in connection with the interpretation of the effects of the control period.

\section{RESULTS}

Status on Admission. The clinical and laboratory findings are those usually seen in moderate to advanced Laennec's cirrhosis (Table I, Figure 1). The preponderance of males can be ascribed, in part at least, to the almost exclusively male population of the Veterans Hospital, where half the subjects were studied. Alcoholism and poor diet appeared to be important features in the past history, although reliable quantitative data could not be obtained. The high incidence of jaundice and ascites testifies to the severity of the disease in most of the cases, and in only one (Case 9v) could the liver be regarded as being in a state of "compensation."

Hepatic enlargement was present in all but two subjects (Cases 10 and 14) and may have been related to the degree of fat infiltration noted histologically, although the causal relationship between the two is by no means certain (35).

The impairment of hepatic function demonstrated by laboratory methods was reasonably well correlated with the clinical status, the most significant findings being an elevation of the serum bilirubin level, increased bromsulphalein retention and a decrease in serum albumin. The serum cholesterol findings were of interest in that the total level was decreased in five, and increased in two. Of the six subjects in whom the cholesterol was fractionated, only two showed a pathological increase in the free : total ratio. The level of serum cholesterol and its fractions did not appear to be 
related to the clinical, functional or histologic status of the liver, nor to its responsiveness to treatment.

The histologic findings were typical of Laennec's cirrhosis. Fatty infiltration of the parenchyma, fibrosis, periportal cellular infiltration and distortion of the architecture of the lobules predominated. Case $9 v$ showed maximal fatty infiltration but no fibrosis, while Case 14 with the most marked fibrosis, showed little fat. No mitotic figures were seen, but the parenchymal cells frequently exhibited variations in size and staining qualities with many large binucleate cells and hyperchromatic nuclei, which were interpreted as probable signs of regeneration. Hyaline necrosis occurred much less frequently than in other studies of biopsy material in Laennec's cirrhosis, and may be related to our use of formalin-absolute alcohol fixative instead of Zenker's fluid (18). The individual histologic find- ings were poorly correlated with specific tests of liver function, or with particular clinical manifestations, and their severity reflected only in a very general way the severity of the disease clinically. In Volwiler's experience there has been a similar poor correlation of histologic, functional and clinical findings (18).

Changes Observed at the end of the Control Period. Improvement in the clinical, functional and morphological status of the liver occurred in a significant number of the subjects (Tables II and III, Figure 2). The degree of improvement varied from case to case, and was not uniform by all criteria, but it appeared to be roughly correlated with the initial severity of the fat infiltration, an observation previously noted by others $(18,36)$. Thus, striking improvement occurred in Case $9 \mathrm{v}$ with the most marked fat infiltration (Figure 3),

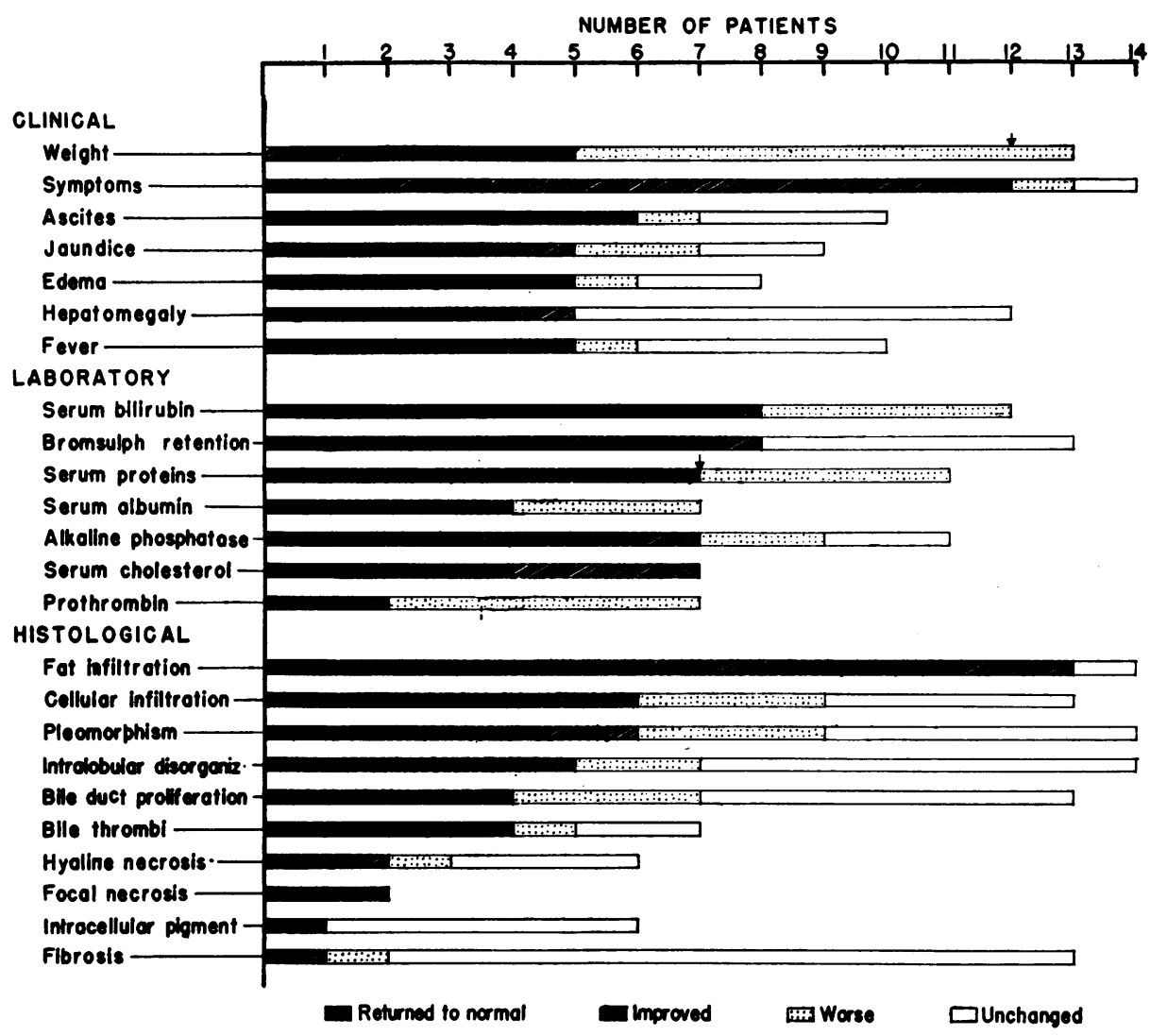

Fig. 2. Changes Noted During Control Period

The total length of the bars indicate the number of abnormal findings at the beginning of the control period, except in the case of weight and serum proteins where the original number of abnormal values is indicated by an arrow.

In the histological data \pm values were regarded as within normal limits. An increase in pleomorphism was regarded as a sign of regeneration and improvement. 


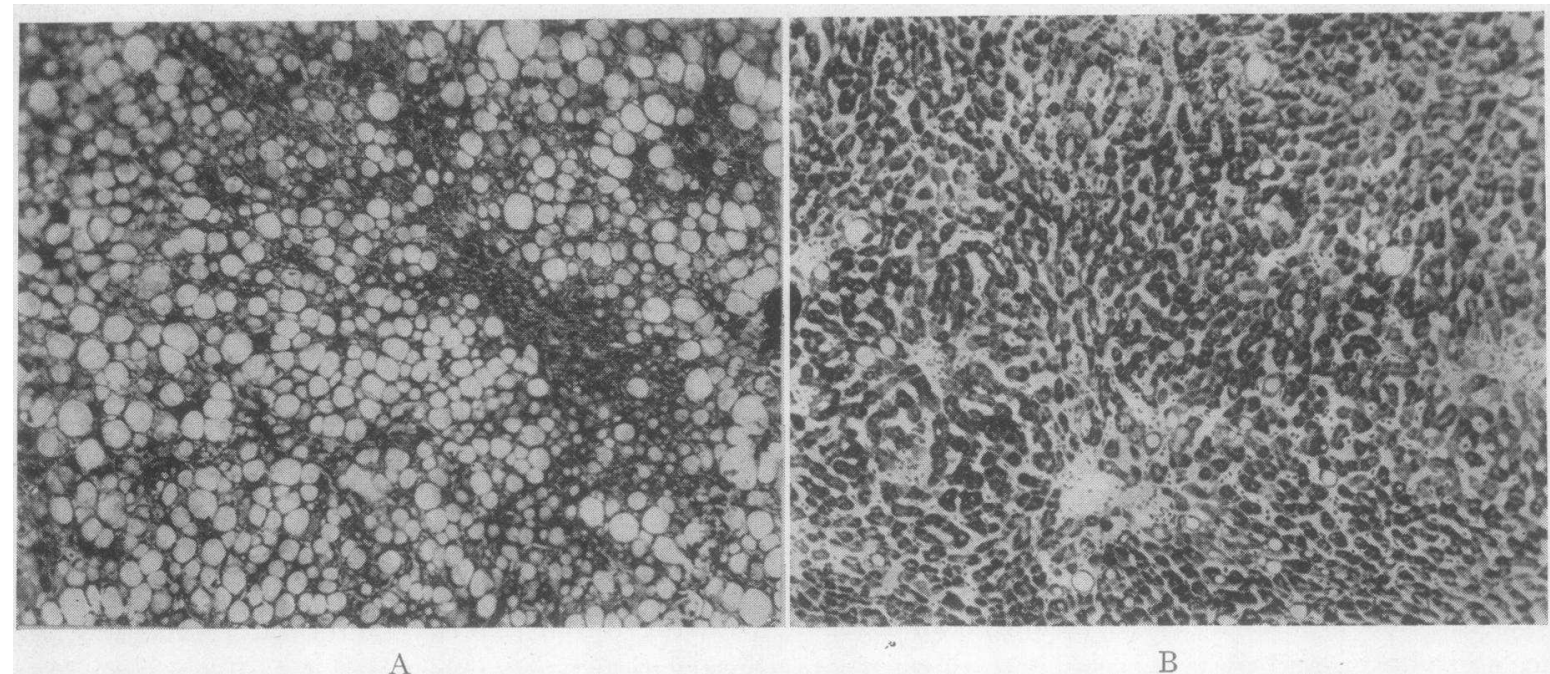

Fig. 3. Liver Biopsy, Case 9v

A. Before treatment, showing marked fat infiltration without significant fibrosis, distortion of the lobular architecture, and small compressed parenchymal cells (hematoxylin and eosin $\times 150$ ).

B. Forty-two days on control regime, showing almost complete loss of fat and restoration of normal lobular architecture and normal liver cords (Best's carmine $\times 150$ ). The liver had returned to normal size, and function tests were within normal limits at this time.

while the clinical course was rapidly and progressively downhill in Case 14 with minimal fat infiltration, even after the basic regime was replaced by a high protein, high caloric diet supplemented with choline and parenteral vitamins, liver extract and serum albumin.

The appearance of a complicating infection affected the course of the disease unfavorably in at least two subjects. Case 1 showed subjective and objective improvement during the first two weeks of the control period, but became more jaundiced, developed edema and exhibited an, increase in ascites and a decrease in his serum proteins concomitant with the onset of a severe penicillinresistant streptococcal sore throat in the third week. Unfortunately the control period was terminated at this point and choline was added to the basic regime. As the infection subsided there was clinical and functional improvement again. The cirrhosis was complicated by an unexplained suppurative peritonitis in Case 10, and there was little improvement during the control period except for a slight fall in the serum bilirubin level, and a decrease in fat infiltration histologically. Significant improvement did not occur until the infection was brought under control by surgical drainage of the abdomen combined with chemotherapy.

Subjective improvement in the initial symptoms was observed in all the cases, except 10 and 14 . This was accompanied by a decrease or loss of ascites, edema, jaundice, hepatomegaly and fever in more than a third of the group. Ascites subsided completely in five cases and decreased in one. The ascites was sufficiently severe in these to have required paracentesis in four.

Clinical improvement was usually accompanied by evidence of improved hepatic function, although there were several notable exceptions. Approximately half the subjects exhibited a fall in serum bilirubin and bromsulphalein retention and a rise in serum protein and albumin. In a significant number these values returned to normal. There was a fall in serum protein despite improvement by other criteria in two instances. In Case 4 the fall was due to a decrease in globulin without a significant change in the albumin fraction. In Case 10 both the total protein and albumin fraction fell despite morphologic improvement and a slight decrease in serum bilirubin. The fall in serum albumin in this instance may have been related to a loss by paracentesis and to an inadequate protein intake in the face of infection, rather than to a deterioration of hepatic function.

The changes in serum cholesterol were of interest. In every instance where the level was abnormal there was a rise or fall toward the nor- 
mal range, depending on whether the initial value was low or high. The free: total cholesterol ratio was followed in only three subjects. Initially the ratio was abnormally high in two and normal in the third. It fell to normal in one, declined slightly in the second and did not change significantly in the third.
The changes in cephalin-cholesterol flocculation and thymol turbidity were not considered significant. The prothrombin level fell in five cases, but the fall was significant in only one instance (Case $5 \mathrm{v}$ ). Only Case $2 \mathrm{v}$ showed a significant increase in prothrombin.

The most striking change observed histologically

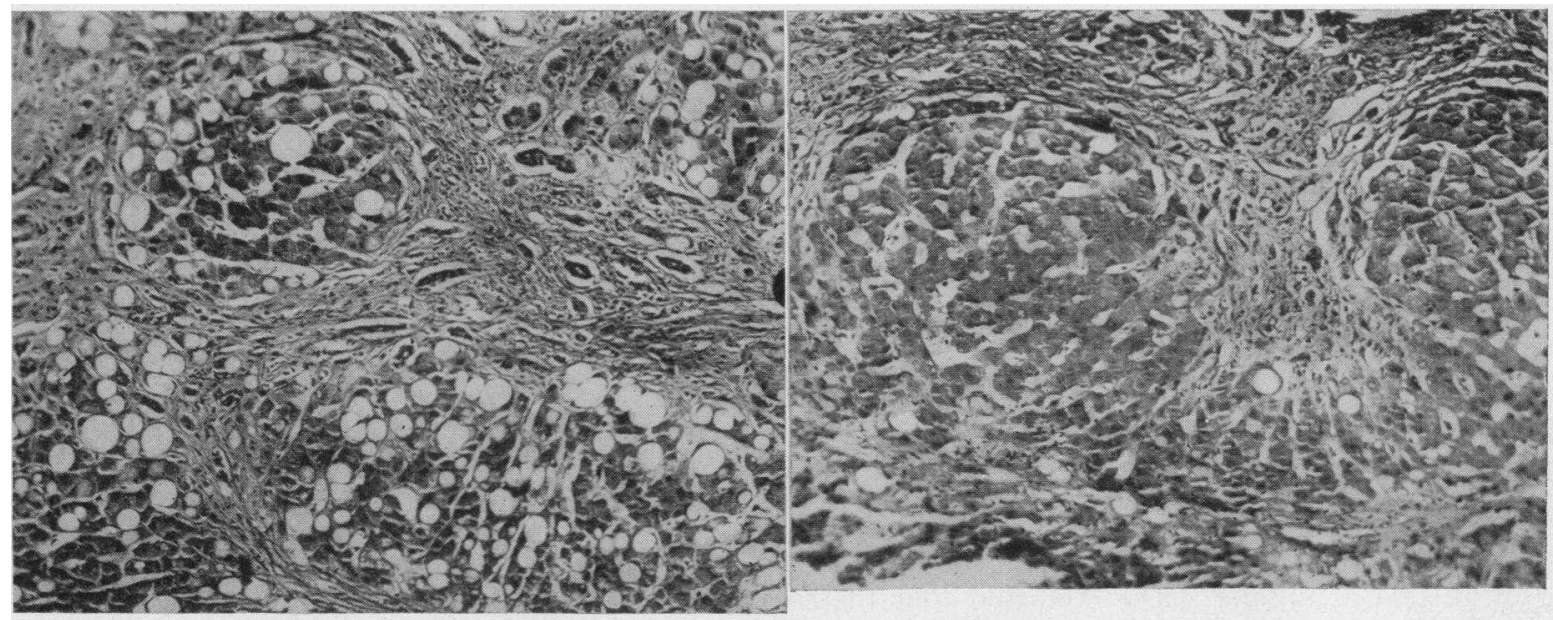

A

B

Fig. 4. Liver Biopsy, Case 2v

A. Before treatment, showing marked fibrosis, moderate fat infiltration, disruption of the normal lobular architecture, and bile duct proliferation (hematoxylin and eosin $\times 150$ ).

B. Twenty-eight days on control regime, showing a significant decrease in fat and larger, more normal appearing liver cords (hematoxylin and eosin $\times 150$ ). The liver had decreased in size, and function tests were within normal limits at this time.

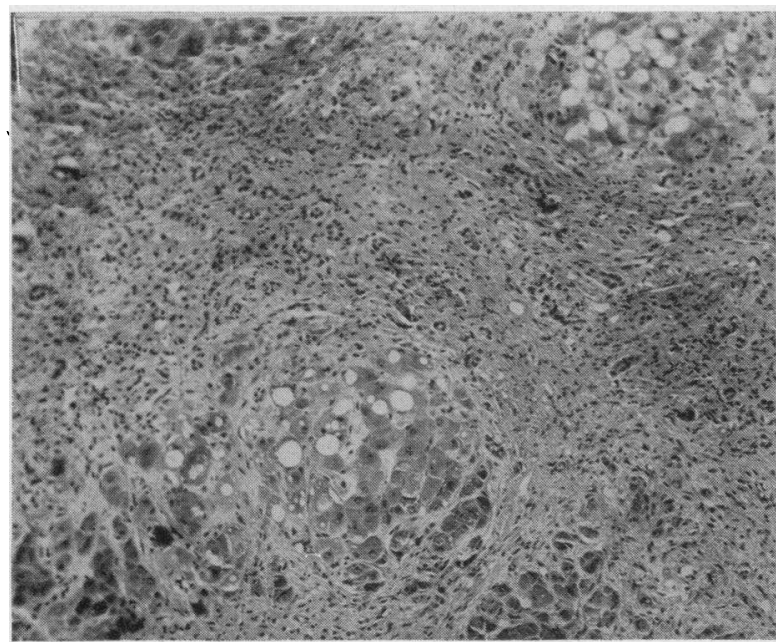

A

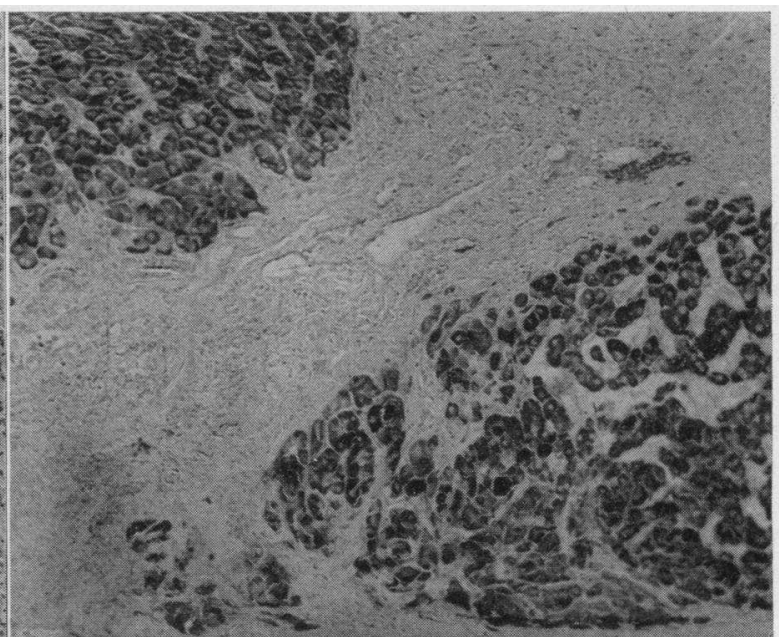

B

Fig. 5. Liver Biopsy, Case 14

A. Before treatment, showing very extensive fibrosis, marked disruption of the lobular architecture, bile duct proliferation, and slight fat infiltration (hematoxylin and eosin $\times 150$ ).

B. Thirty-two days on control regime, showing complete loss of fat despite obvious deterioration of clinical and functional status. The apparent shrinkage of the liver cords is due to the stain employed (Best's carmine $\times 150$ ). 
was a decrease in fat infiltration which occurred in all but one subject (Figures 3-5). The fat actually disappeared in three instances, including Case 14 whose clinical and functional status deteriorated (Figure 5). Further evidence of healing was found in the increased regeneration of parenchymal cells, the decrease in periportal cellular infiltration and the improvement in intralobular organization, which occurred in almost half the cases. The other signs of histologic improvement noted in Table III occurred less frequently. There was no significant decrease in fibrosis in any of the cases.

The validity of the method of sampling the liver by needle biopsy is obviously open to some question, but the uniform trend of the changes observed suggests that they were of significance.

\section{COMMENT}

It is apparent from these observations that significant improvement may occur in Laennec's cirrhosis under conditions of bed-rest, alcohol withdrawal, and a minimal basic diet, and that these factors must be taken into consideration in evaluating the specific therapeutic actions of dietary supplements. The results, however, do not warrant any definite conclusions regarding the relative efficacy of the basic diet and diets supplemented with protein or lipotropes, nor do they indicate which of the factors in the control regime was responsible for the apparent improvement observed.

The six subjects who received supplements of choline in Period II and of protein in Period III, under continued conditions of bed-rest and alcohol restriction, showed progressive improvement clinically and histologically. Since there was no significant change in the rate of recovery, as compared to that in Period I, it could not be determined whether the observed effects were due to the specific action of these supplements, or to prolongation of the period of bed-rest and alcohol withdrawal. It may not be possible to evaluate the role of dietary supplements in the treatment of cirrhosis until the factors responsible for improvement during the control period are better understood, and until the maximum effects of the basic regime have been determined.

The methods of study employed by Volwiler and his associates (18) were sufficiently similar to ours to permit some comparisons of the effects of their high protein, high caloric diet with those of the basic diet used in these experiments, under the same conditions of restricted activity in a hospital. There was no significant difference in the clinical improvement observed in the two groups, but the subjects on the better diet showed more complete removal of fat histologically, and greater and more consistent increases in serum albumin. These differences, however, may not have been due to the diet, since Volwiler's subjects were less severely ill than ours, judged both clinically by the incidence of ascites and jaundice, and histologically by the degree of fibrosis present. Only four of his 13 subjects had ascites, compared to 10 of the 14 on the basic diet, and only six showed more than one-plus fibrosis histologically, compared to 13 in our group. On both diets the only significant rises in serum protein occurred in the non-ascitic group, and in several instances the level fell when ascites was present. There was no clear-cut correlation, however, between the degree of fibrosis and the rate of fat removal from the liver. While the differences in the rate of fat removal in the two groups may have been related to differences in the severity and duration of the disease, the possibility that they were due to the diet cannot be excluded.

Franklin and his associates (17) have also studied cirrhotics by the serial biopsy technique, and have concluded that supplements of choline and methionine have specific therapeutic effects. Their results are difficult to interpret since they had no control group, and since their basic diet had a relatively high protein and caloric content and included large supplements of vitamins. Volwiler (18). under somewhat different conditions, on the other hand, has found that lipotropes do not augment the effects of a high protein diet. Franklin's comments are of interest in connection with the observations being reported: "Shorter periods of observation are desirable in view of possible spontaneous remissions which may occur with longer control periods. Even in the shorter periods used in this study, however, the possibility of spontaneous improvement may raise difficulties in evaluating the role of therapy."

Further work is needed to determine what factors were operative during our control period to account for the improvement which occurred. 
The possibility cannot be excluded that the basic diet employed was an important factor. The optimal protein requirement for the normal adult is still a matter of speculation, and it is known to be influenced by a great many factors. The standard of $1 \mathrm{gm}$. per kilogram of body weight daily, however, is widely accepted, and it is generally agreed that larger amounts are required in overcoming malnutrition and in facilitating tissue repair. Accordingly, the requirement in cirrhosis is usually given as 1.75 to $2.0 \mathrm{gm}$. per kilogram, although it is recognized that these values have not been established under varying dietary conditions (18). By this standard the basic diet was suboptimal in regard to protein. While the caloric supply appeared to be inadequate for some of the subjects, there was no clear-cut evidence that there was a deficiency of protein. Eight of the subjects lost weight on the diet, but in only a few was there obvious tissue wasting, while in the others a decline in weight due to water loss could not be excluded. It is quite possible that under the experimental conditions of bed-rest, a moderate carbohydrate supply and a maintenance caloric intake, $1 \mathrm{gm}$. of protein per kilogram met both the general nutritional needs and the specific requirements of the liver. The somewhat slower removal of fat from the liver, compared to Volwiler's experience (18), and the fall in serum proteins in some of the subjects are the only indications that the protein intake may have been suboptimal in some instances.

The nutritional requirements of the liver are not known precisely, nor have the factors which influence them been studied in man. In animals, at least, there appears to be a relationship between the requirement of lipotropic substances and the over-all metabolic activity (37). Thus, deficient diets which retard growth (38), starvation (39) and the administration of thiouracil (40), lower the choline requirements of rats. There is suggestive evidence that a similar relationship may exist in man. Low protein diets known to produce fatty infiltration and cirrhosis of the liver in children are usually high in carbohydrate and caloric content (41). Low caloric, low protein diets, on the other hand, do not produce liver damage in man, under some circumstances at least (42). It is conceivable, then, that the decrease in liver fat observed in our experiments, and even the improvement in liver function, were starvation effects.
This might account for the apparent histologic improvement despite obvious clinical deterioration in Case 14, and for the changes observed in the subjects who lost weight during the experiment, but could hardly account for the improvement which occurred in those who gained weight.

If the choline requirement of the liver is related to the caloric intake, alcoholism may play a dual role in creating a choline deficiency-first, by raising the caloric intake without a concomitant increase in protein, and secondly, by reducing the food intake. The caloric value of alcohol is usually disregarded even in well-controlled, pairedfeeding experiments (20), and may account for the apparent failure of a normal protein intake to protect the liver against fat infiltration. Moreover, a large enough supplement of choline or protein might prevent or reduce fat infiltration and mask the effects of alcohol, and might account for the failure of some observers $(11,18)$ to demonstrate any deleterious effects when alcohol is administered to cirrhotics on high-protein diets.

The importance of bed-rest in acute liver disease has been recognized for some time, and recently it has been stressed in the treatment of cirrhosis (18). It is not known whether rest exerts its favorable action by promoting healing, as it does in other inflammatory diseases, or whether it does so by altering the metabolic activities of the liver in some equally obscure way. The decrease in hepatic blood flow during exercise (43) may be of importance in this connection. The degree of physical activity may also be one of the factors which determine the lipotropic requirement of the liver, just as in the case of the rate of growth.

It should be emphasized that whatever the specific effects of the diet on the liver prove to be, the patient with Laennec's cirrhosis will still require a well-balanced diet to overcome the usually associated malnutrition. Future studies may reveal that dietary supplements have no specific effects on the liver, but rather improve the nutrition generally permitting the liver to heal under more favorable conditions.

\section{SUMMARY AND CONCLUSIONS}

1. Significant clinical, functional and histological improvement has been observed in patients with Laennec's cirrhosis under controlled condi- 
tions of bed-rest, alcohol withdrawal and a minimal basic diet.

2. The effects of such a control period must be taken into account in evaluating the specific effects of dietary supplements on the liver.

3. The results do not warrant any conclusions regarding the relative importance of bed-rest, alcohol withdrawal and diet in producing the effects observed during the control period.

\section{BIBLIOGRAPHY}

1. MacLean, D. L., and Best, C. H., Choline and liver fat. Brit. J. Exper. Path., 1934, 15, 193.

2. Rich, A. R., and Hamilton, J. D., The experimental production of cirrhosis by means of a deficient diet. Bull. Johns Hopkins Hosp., 1940, 66, 185.

3. Griffith, W. H., Choline metabolism; the effect of cystine, fat, and cholesterol on hemorrhagic degeneration in young rats. J. Biol. Chem., 1940, $132,639$.

4. Blumberg, H., and McCollum, E. V., The prevention by choline of liver cirrhosis in rats on high fat, low protein diets. Science, 1941, 93, 598.

5. György, P., and Goldblatt, H., Experimental production of dietary liver injury (necrosis, cirrhosis) in rats. Proc. Soc. Exper. Biol. \& Med., 1941, 46, 492.

6. Lowry, J. V., Daft, F. S., Sebrell, W. H., Ashburn, L. L., and Lillie, R. D., Treatment of dietary liver cirrhosis in rats with choline and casein. Pub. Health Rep., 1941, 56, 2216.

7. Himsworth, H. P., and Glynn, L. E., Massive hepatic necrosis and diffuse hepatic fibrosis (acute yellow atrophy and portal cirrhosis); their production by means of diet. Clin. Sc., 1944, 5, 93.

8. Dutra, F. R., and McKibbin, J. M., The pathology of experimental choline deficiency in dogs. J. Lab. \& Clin. Med., 1945, 30, 301.

9. Gillman, J., Gillman, T., Mandelstam, J., and Gilbert, C., The production of severe hepatic injury in rats by the prolonged feeding of maize-meal porridge (mealie-pap) and sour milk. Brit. J. Exper. Path., 1945, 26, 67.

10. Eilert, M. L., and Dragstedt, L. R., Lipotropic action of lipocaic: a study of the effect of oral and parenteral lipocaic and oral inositol on the dietary fatty liver of the white rat. Am. J. Physiol., 1946, $147,346$.

11. Patek, A. J., Jr., and Post, J., Treatment of cirrhosis of the liver by a nutritious diet and supplements rich in vitamin B complex. J. Clin. Invest., 1941, 20, 481.

12. Broun, G. O., and Muether, R. O., Treatment of hepatic cirrhosis with choline chloride and diet low in fat and cholesterol. J. A. M. A., 1942, 118, 1403.
13. Russakoff, A. H., and Blumberg, H., Choline as an adjuvant to the dietary therapy of cirrhosis of the liver. Ann. Int. Med., 1944, 21, 848.

14. Beams, A. J., The treatment of cirrhosis of the liver with choline and cystine. J. A. M. A., 1946, 130, 190.

15. Kimball, S., and Chapple, W. H. C., Laennec's cirrhosis: the effect of therapy in increasing life expectancy. Gastroenterology, 1947, 8, 185.

16. Morrison, L. M., New methods of therapy in cirrhosis of the liver. J. A. M. A., 1947, 134, 673.

17. Franklin, M., Salk, M. R., Steigmann, F., and Popper, H., Clinical, functional and histologic responses of fatty metamorphosis of human liver to lipotropic therapy. Am. J. Clin. Path., 1948, 18, 273.

18. Volwiler, W., Jones, C. M., and Mallory, T. B., Criteria for the measurement of results of treatment in fatty cirrhosis. Gastroenterology, 1948, $11,164$.

19. Wade, L., Neudorff, L., Fritz, H., and Karl, M., The effect of choline, methionine, and low fat diet on the life expectancy of patients with cirrhosis of the liver. J. Lab. \& Clin. Med., 1948, 33, 1123.

20. Ashworth, C. T., Production of fatty infiltration of the liver in rats by alcohol in spite of adequate diet. Proc. Soc. Exper. Biol. \& Med., 1947, 66, 382.

21. Capps, R. B., and Barker, M. H., The management of infectious hepatitis. Ann. Int. Med., 1947, 26, 405.

22. Connor, C. L., The etiology and pathogenesis of alcoholic cirrhosis of the liver. J. A. M. A., 1939, $112,387$.

23. Malloy, H. T., and Evelyn, K. A., The determination of bilirubin with the photoelectric colorimeter. J. Biol. Chem., 1937, 119, 481.

24. Hanger, F. M., Serological differentiation of obstructive from hepatogenous jaundice by flocculation of cephalin-cholesterol emulsions. J. Clin. Invest., 1939, 18, 261.

25. MacLagan, N. F., Thymol turbidity test: a new indicator of liver dysfunction. Brit. J. Exper. Path., 1944, 25, 234.

26. Gaebler, O. H., Determination of bromsulphalein in normal, turbid, hemolyzed, or icteric serums. Am. J. Clin. Path., 1945, 15, 452.

27. Bodansky, A., Notes on the determinations of serum inorganic phosphate and serum phosphatase activity. J. Biol. Chem., 1937, 120, 167.

28. Quick, A. J., Determination of prothrombin. Proc. Soc. Exper. Biol. \& Med., 1939, 42, 788.

29. Sparkman, R., Studies of urobilinogen; a simple and rapid method for quantitative determination of urobilinogen in stool and in urine. Arch. Int. Med., 1939, 63, 858.

30. Wallace, G. B., and Diamond, J. S., The significance of urobilinogen in the urine as a test for liver function. Arch. Int. Med., 1925, 35, 698. 
31. Phillips, R. A., van Slyke, D. D., Dole, V. P., Emerson, K., Jr., Hamilton, P. B., and Archibald, R. M., The copper sulfate method for measuring specific gravities of whole blood and plasma. Bull. U. S. Army Med. Dept., 1943, 71, 66.

32. Peters, J. P., and Man, E. B., The interrelations of serum lipids in normal persons. J. Clin. Invest., 1943, 22, 707.

33. Bloor, W. R., The determination of cholesterol in blood. J. Biol. Chem., 1916, 24, 227.

34. King, E. J., and Armstrong, A. R., Convenient method for determining serum and bile phosphatase activity. Canad. M. A. J., 1934, 31, 376.

35. Best, C. H., McCartney, J. S., and MacNider, W. deB., Discussion on Report of Pathologists on Cirrhosis. Trans. Sixth Conf. on Liver Injury, May 1-2, 1947, Josiah Macy, Jr. Foundation, New York, pp. 17-18.

36. Davis, W. D., Jr., Prognostic value of biopsy in cirrhosis of the liver. Proc. Central Soc. Clin. Res., 1947, 20, 63.

37. Mulford, D. J., and Griffith, W. H., Choline metabo- lism. VIII. The relation of cystine and of methionine to the requirement of choline in young rats. J. Nutrition, 1942, 23, 91.

38. Treadwell, C. R., Growth and lipotropism. I. The dietary requirements of methionine, cystine and choline. J. Biol. Chem., 1945, 160, 601.

39. Best, C. H., and Huntsman, M. E., The effect of choline on the liver fat of rats in various states of nutrition. J. Physiol., 1935, 83, 255.

40. György, P., and Goldblatt, H., Thiouracil in the prevention of experimental dietary cirrhosis of liver. Science, 1945, 102, 451.

41. Waterlow, J. C., Nutritional liver disease in West Indian infants. Proc. Roy. Soc. Med., 1947, 40, 347.

42. Sherlock, S., and Walshe, V., Effect of undernutrition in man on hepatic structure and function. Nature, 1948, 161, 604.

43. Bradley, S., Effect of posture and exercise upon blood flow through the liver. Trans. Seventh Conf. on Liver Injury, Jan. 15-16, 1948, Josiah Macy, Jr. Foundation, New York, pg. 53. 